\title{
Femke Geusens
}

Leuven School for Mass Communication Research, KU Leuven, Belgium

\section{Cabral A. Bigman-Galimore}

Department of Communication, University of Illinois at Urbana-Champaign, USA

\section{Kathleen Beullens}

Leuven School for Mass Communication Research, KU Leuven, Belgium

\begin{abstract}
Research indicates a positive relationship between sharing alcohol references on social media and drinking behaviour. The current study extends that line of research by assessing the interaction of risk-related personality traits with alcohol-related social media use to examine whether social media can be used to identify individuals at risk for heavy drinking behaviour. The results of a cross-sectional survey among a sample of 638 college students (aged 18-25) indicate that the positive association between sharing alcohol references on social media and drinking intentions was strongest for individuals with low levels of sensation seeking and sensitivity to peer pressure. There was no significant interaction between sharing alcohol references and selfcontrol. These findings indicate that the relationship between sharing alcohol references and drinking intentions is not uniform for all individuals, and that risk-related individual differences should be considered in future research and interventions.
\end{abstract}




\section{Keywords}

Social media, alcohol, differential susceptibility, personality

The college years are marked by a significant increase in alcohol consumption (Arnett, 2005; Tan, 2012). Many students perceive alcohol as integral to the college experience and consider drinking and partying the norm and an expected aspect of college life (Colby et al., 2009; Crawford \& Novak, 2006; Tan, 2012; Wicki et al., 2010). Research on the substance use patterns of emerging adult college students in Belgium, a country with a tolerant alcohol policy and a legal drinking age of 16, demonstrates that about one-fourth of college students engage in binge drinking at least once per month, and one in two students are hazardous drinkers, potentially at risk for active alcohol use disorders (Van Damme et al., 2018). This is worrisome, because heavy alcohol consumption has not only been linked with negative social and personal consequences, such as missing class or getting injured (De Bruyn et al., 2018), but also with an overall reduced quality of life (Dormal et al., 2018).

During the past few years, social media has been identified as a potential predictor of alcohol consumption. A recent meta-analysis demonstrated that greater alcohol-related social media use is related to both greater self-reported drinking and alcohol-related problems (Curtis et al., 2018). Likewise, a large-scale four-country study demonstrated that daily use of Facebook, Instagram, YouTube, Twitter and instant messaging was associated with higher hazardous drinking patterns, though national differences existed (Savolainen et al., 2020). The present study adds to this line of literature in two ways. First, it focuses on an important but understudied domain of media research, namely social media self-effects. Although self-sharing has been demonstrated to predict alcohol consumption (D'Angelo et al., 2014; Geusens \& Beullens, 2017b; Moreno et al., 2013), and prior research has demonstrated that self-sharing of one's own content and exposure to others' content are differently associated with risky drinking behaviour (Geusens \& Beullens, 2018, 2019), few researchers are looking at how self-sharing is associated with young people's drinking behaviour. Second, the present study aims to advance our collective knowledge by answering the call to investigate the conditionality of media effects (Krcmar, 2009; Slater et al., 2003; Valkenburg \& Peter, 2013). Conditionality means that under certain conditions, media effects can be more influential (Valkenburg \& Peter, 2013). In order to better understand alcohol-related social media effects, it is important to identify these conditional effects. Therefore, the second contribution of this study is to examine the interactions between sharing alcohol references and three risk-related personality traits: sensation seeking, sensitivity to peer pressure and self-control.

\section{Self-Effects of Sharing Alcohol References on Social Media}

Alcohol references are omnipresent on social media (Beullens \& Schepers, 2013; Hendriks et al., 2018; Moreno et al., 2010). For example, Beullens and Schepers (2013) reported that over 95\% of the sampled Facebook profiles contained pictures referencing alcohol use. Hendriks and her team reported that half of their participants shared alcohol references on Facebook, and one out of three shared this type of content on Instagram (Hendriks et al., 2018). Most often, alcohol references are 
shared to show others that the individual was present at a fun event and to share the fun of the moment (Hendriks et al., 2017). Alcohol is typically portrayed in a moderate and socially acceptable way, either in the background or as the focus of the picture; heavy drinking references such as pictures depicting drunkenness or drinking games are less frequent (Hendriks et al., 2018). Overall, it appears that most of the alcohol references shared online are derived from real-life drinking experiences, thus reflecting offline drinking behaviours (Hebden et al., 2015; Hendriks et al., 2017). Nevertheless, sharing such online alcohol-related references has been shown to affect future alcohol consumption as well (D'Angelo et al., 2014; Geusens \& Beullens, 2017b; Moreno et al., 2013). Theoretically, it has been argued that content creators can internalize their online selfpresentation (Bem, 1972; Valkenburg, 2017): By presenting themselves as people who enjoy drinking alcohol, individuals can unconsciously persuade themselves that this is part of who they are, which can result in increased alcohol consumption. It has already been demonstrated that the more someone engages in heavy drinking behaviour, the more alcohol references they share (Geusens \& Beullens, 2017b). By sharing more alcohol references, they simultaneously increase their engagement in heavy drinking behaviour. However, what remains understudied is how this relationship works.

One potential mechanism through which social media use could be related to drinking behaviour lies in drinking intentions. According to fundamental and regularly substantiated models of behavioural prediction, intentions are one of the most important underlying factors of behaviour (Ajzen, 1991; Cooke et al., 2016). For example, research from other areas of risk-related social media self-effects has demonstrated that sharing pro-smoking messages on social media predicts smoking intentions (Yoo et al., 2016). For drinking, it has repeatedly been demonstrated that heavy drinking behaviour among emerging adults can be highly intentional (Trim et al., 2011; Zajdow \& MacLean, 2014). In addition, a cross-cultural study comparing students aged 18-20 who would be considered of age in one country (Belgium, with a legal drinking age of 16) but underage in the other country (the United States, with a legal drinking age of 21) found that sharing alcohol references can predict drinking intentions in both samples, though there are differences in how this relationship operates depending on the legal status of the students (Geusens, Bigman-Galimore, \& Beullens, 2019). Thus, taken together, we can expect that sharing alcohol references more often is associated with greater intentions to consume alcohol (Hypothesis 1). Considering prior longitudinal data that demonstrated a reciprocal relationship between sharing alcohol references and binge drinking (Geusens \& Beullens, 2017b) and the cross-sectional nature of the present study, this association between sharing alcohol references on social media and drinking intentions can be both indicative (i.e., drinking intentions predict self-sharing) or predictive (i.e., self-sharing predicts drinking intentions).

\section{The Interaction Between Personality and Sharing Alcohol References on Social Media}

Scholars have called for the examination of non-media variables, such as personality, as moderators of media effects in order to fully understand for whom media effects are most influential (Krcmar, 2009; Slater et al., 2003; Valkenburg \& Peter, 2013). These scholars posit that 
some individuals are more responsive to media than others, and individual differences and social contexts can shape the direction and/or strength of media effects. This implies that media effects are not equal for all media users, and it is important to identify which subgroups experience the strongest association between media use and other behaviour. According to Valkenburg and Peter (2013), there are three types of differential-susceptibility variables: dispositional, developmental and social. Dispositional susceptibility relates to all personal dimensions (e.g., gender, personality, values, moods, etc.). Developmental susceptibility relates to cognitive, emotional and social development. Social susceptibility relates to all social-context factors (e.g., peers, workplace, cultural norms, etc.). This study focuses on personality as a dispositional susceptibility variable.

\section{Personality as a Dispositional Susceptibility Variable}

Prior research has investigated the role of personality traits in alcohol consumption. For example, studies have found that drinking behaviour can be predicted by different aspects of the five-factor model (i.e., the 'Big Five') (Hakulinen et al., 2015; Malouff et al., 2007) and impulsivity (Coskunpinar et al., 2013; Stautz \& Cooper, 2013). The present study builds on lines of research that have examined sensation seeking (Hittner \& Swickert, 2006), sensitivity to peer pressure (Griffin et al., 2015) and self-control (Wills \& Stoolmiller, 2002) as predictive personality traits for alcohol consumption. These three risk-related personality traits play a central role in young people's drinking and also have direct bearing on intervention strategies (e.g., tailoring media to appeal to risk-seeking populations and boosting social skills and efficacy surrounding drinking behaviour).

Sensation seeking can be understood as the need to experience novel and varied sensations and situations, and the willingness to take risks and use substances to achieve these sensations (Hoyle et al., 2002). Sensitivity to peer pressure relates to difficulty saying 'no' to others, including about illegal or risky behaviours (Santor et al., 2000), while self-control relates to the capacity to change and adapt the self by overriding one's thoughts, emotions and impulses and by interrupting undesired behavioural tendencies (Tangney et al., 2004). Each of these personality traits has been linked to risky drinking behaviour. In particular, two meta-analyses on impulsivity as a risk factor for alcohol use found that sensation seeking was the most important impulsivity construct for binge drinking (Coskunpinar et al., 2013; Stautz \& Cooper, 2013). Individuals with low self-control have been shown to have more problematic drinking patterns (Koning et al., 2011; Tangney et al., 2004; Wills \& Stoolmiller, 2002), and behavioural self-control training is proven to be an effective intervention method for alcohol abuse (Walters, 2000). Finally, several studies have indicated that, because alcohol is a highly social behaviour, especially those with high sensitivity to peer pressure consume more alcohol (e.g., Daw et al., 2013; Griffin et al., 2015; Mrug \& Windle, 2014).

The personality traits under consideration in this study have not only been shown to predict heavy alcohol consumption using quantitative research methods (see above) but also reflect motives behind college drinking and online alcohol-related communication that emerge from studies employing more qualitative approaches. For college students, binge drinking stems from a desire to fit in and to have fun with friends, a yearning to lose control, a longing to gain independence from parents and guardians and a desire to experience careless fun (Kubacki et al., 2011). Likewise, for some, sharing alcohol-related content on social media is argued to be an 
expression of their social identity and friendship-group belonging, a way to augment drinking experiences and a form of entertainment for self and others (Hebden et al., 2015; Niland et al., 2014). Simultaneously, it has been argued that especially those who aim to portray a wild or offensive image are most likely to share alcohol references on their social media profiles (Peluchette \& Karl, 2009). These meanings of alcohol-related communication expressed by those who are sharing alcohol references tie into sensation seeking and sensitivity to peer pressure. Nevertheless, online alcohol-related communication is also a careful balancing act in which selfpresentation is a managed risk by which individuals show that they are in control over their own intoxication levels (Hebden et al., 2015; Niland et al., 2014), thus relating to self-control.

Taken together, considering the research on the relationship between sensation seeking, sensitivity to peer pressure, and self-control and heavy drinking behaviour, as well as the link between these three personality traits and the motives behind college students' heavy drinking behaviour and online alcohol-related content communication, the present study operationalizes a 'high-risk personality' as having high levels of (a) sensation seeking or (b) sensitivity to peer pressure, or (c) low levels of self-control. Thus, high sensation seeking, high sensitivity to peer pressure and low self-control were expected to independently and positively correlate with drinking intentions (Hypothesis 2).

\section{Downward Spirals and Desensitization}

To return to the proposition that personality is a potential differential-susceptibility factor in alcohol-related social media self-effects, several scholars have called for research on the conditionality of media effects, because while the average media effect is small to moderate, some individuals are expected to be more responsive to media content (Krcmar, 2009; Slater, 2004; Valkenburg \& Peter, 2013). In answer to this call, the present study is the first to test whether and how risk-related personality traits interact with sharing alcohol references on social media as indicators of drinking intentions. Thus, this study investigates which groups of users can be identified as at risk for heavy drinking behaviour by the alcohol references they share on social media. Identifying for whom the relationship between alcohol-related social media use and drinking intentions is strongest is not only relevant from a theoretical perspective, as this engenders a more profound understanding of media effects, but also from a practical perspective, as this can help us to identify young people at risk for heavy drinking behaviour based on online behavioural indicators.

When looking specifically at alcohol-related social media effects, it is unclear what the relationship between high-risk personality traits and media effects will be. On the one hand, there is a possibility that the interaction will reflect a downward-spiral model (Slater, 2004; Slater et al., 2003). This would mean that individuals with higher risk traits potentially experience a stronger media effect, which reinforces existing personality-based inclinations, specifically their intentions to drink. On the other hand, desensitization (Funk, 2013; Wolpe, 1982) and ceiling-effects hypotheses (Cramer \& Howitt, 2004) could lead to an opposite pattern of effects. Following the desensitization hypothesis (Funk, 2013; Wolpe, 1982), it could be argued that those who have the most experience with sharing alcohol references experience the weakest association between sharing alcohol references and drinking behaviour, because they are so habituated to this media 
content that they are no longer affected by it (Funk, 2013; Wolpe, 1982). Likewise, it could also be argued that the added impact of media use on these individuals' drinking behaviour is low, because the drinking intentions of those highest in sensation seeking and sensitivity to peer pressure, and lowest in self-control, are already likely to be relatively high, resulting in no extra intention to consume alcohol when sharing alcohol-related content. This would reflect a ceiling effect (Cramer \& Howitt, 2004). A ceiling effect could potentially result from desensitization, though it is also possible that these individuals never experienced a media effect in the first place because the cognition or behaviour under consideration is already at its peak level before engaging with the media content. It should be noted that it is possible that, over time, desensitization follows from a downward spiral (Slater, 2007), but due to the cross-sectional nature of our study, we will test these theories as opposing hypotheses. Thus, considering the two potential directions of this interaction outlined by the downward-spiral model on the one hand and the ceiling effect and desensitization hypotheses on the other hand, we propose the following research question:

RQ1: Do (a) sensation seeking, (b) sensitivity to peer pressure and (c) self-control moderate the relationship between sharing alcohol references on social media and drinking intentions?

\section{Method}

\section{Sample}

Data were collected from 33 colleges and universities in Belgium, a country where alcohol consumption is generally accepted and is legal from the age of 16 . During the second semester of the academic year, 30 research assistants recruited approximately 20 respondents each via email, Facebook or face-to-face contact. Potential candidates were asked to participate in a study on leisure activities by completing a web survey at home. The study was approved by the ethical review board of the authors' institution. In total, 645 college students completed the questionnaire. One-third (32.3\%) of the sample were enrolled in a professional bachelor's degree, $34.3 \%$ in an academic bachelor's degree, $22.7 \%$ in a master's degree and $10.7 \%$ in something else (e.g., a preparation year between obtaining a professional bachelor's degree and starting the master's programme). Females were overrepresented in the sample $(65.8 \%$ females), half of respondents still lived with their parents $(49.8 \%)$, and their ages ranged from 18 to 25 years $(M=20.8$, $S D=1.6)$. Seven people (1.2\%) indicated they were either younger than 18 and not yet a student or older than 25 and no longer a student, and these were dropped from the sample. Thus, the total sample on which the analyses were conducted consisted of 638 emerging adults enrolled in a college or university.

\section{Measures}

Sharing alcohol references on social media was measured using a scale adapted from Beullens and Vandenbosch (2016), which has previously been used among late adolescents by Geusens and Beullens (2017a, 2018, 2019). Respondents were asked how often they (1) privately and (2) publicly shared the following items on any social medium: (a) photos or movie clips or (b) textual 
updates referring to (I) going out, ${ }^{1}$ (II) alcohol use or (III) being drunk. 'Private sharing' was defined as 'references shared with a limited amount of people, e.g., through communication via direct messaging, private groups or group chats'. Responses ranged from 0 (never) to 6 (several times a day). Confirmatory factor analysis for all measures is discussed under 'Measurement Model'.

Intention to consume alcohol was measured using six items, based on guidelines by Fishbein and Ajzen (2010). Respondents were asked to indicate on a 5-point Likert scale whether they intended to (1) consume alcohol, (2) engage in binge drinking or (3) get drunk in the coming (a) month and (b) year. Binge drinking was defined as consuming more than four glasses (females) or five glasses (males) of alcohol within a timespan of two hours. Responses ranged from 1 (strongly disagree) to 5 (strongly agree).

Sensation seeking was measured using the eight-item brief sensation-seeking scale (e.g., 'I would like to explore strange places') (Hoyle et al., 2002). Responses ranged from 1 (strongly disagree) to 5 (strongly agree).

Sensitivity to peer pressure was measured using Santor et al.'s (2000) 11-item short measure of peer pressure (e.g., 'I give in to peer pressure easily'). Responses ranged from 1 (strongly disagree) to 5 (strongly agree).

Self-control was measured using Tangney et al.'s (2004) 13-item brief self-control measure (e.g., 'I am good at resisting temptation'). Nine items had to be reverse-scored (e.g., 'I have trouble concentrating'). Response categories for all three personality measures ranged from 1 (strongly disagree) to 5 (strongly agree).

Control variables. Gender (male [0] and female [1]), accommodation (with parents/family [0] or on their own/with friends [1]) and age (open question) were added as demographic control variables. Prior drinking behaviour was added as a control variable by asking individuals how many drinks containing alcohol they have on a typical drinking day (Saunders et al., 1993). Finally, perceived exposure to alcohol references from friends was controlled for by asking how frequently they noticed their friends sharing the items described in the sharing measure. Each of these variables have been found to predict drinking behaviour. In particular, women typically consume less alcohol than men (Van Damme et al., 2018), and those who still live with their parents typically consume less alcohol than those who live on their own or with friends (Van Damme et al., 2018). In addition, there are mixed results with regard to age, but some studies find that risky drinking behaviour peaks around age 25 (Wicki et al., 2010); prior behaviour generally influences future behavioural intentions, either through habit strength or as part of a conscious decisionmaking process (Ouellette \& Wood, 1998); and exposure to alcohol references on social media has been linked to greater intentions to consume alcohol (Geusens, Bigman-Galimore, et al., 2019).

\section{Measurement Model}

All variables except gender, accommodation, age and prior drinking behaviour were specified as latent variables to account for measurement error. Sharing of alcohol references was specified as a second-order latent variable (Kenny, 2016). Model fit indicated that the model could be improved 
$\left(\chi^{2}=5606.20, p<.001, \mathrm{RMSEA}(\mathrm{CI})=.07(.07 / .07), \mathrm{CFI}=.80, \mathrm{TLI}=.79, \mathrm{SRMR}=.07, \mathrm{AIC}=\right.$ $88415.291)$. To improve the model fit, the model was respecified following the guidelines by Harrington (2009) and Kenny (2011). In particular, four items had to be removed because they did not load onto their respective scales: The items 'I would like to explore strange places' (factor loading $=.20$ ) and 'I get restless when I spend too much time at home' (factor loading $=.35$ ) were deleted from the sensation-seeking scale, the item 'I have a hard time breaking bad habits' (reversescored, factor loading $=.11$ ) was deleted from the self-control scale and the item 'if a group of people asked me to do something, it would be hard to say no' (factor loading $=.38$ ) was deleted from the sensitivity to peer pressure scale. In addition, the error loadings of the intention to consume alcohol in the coming year and in the coming month had to be covaried $(r=.67)$, as well as the error loadings between the intention to engage in binge drinking in the coming year and in the coming month $(r=.50)$, between the sensitivity to peer pressure items 'my friends could push me into doing just about anything' and 'I give into peer pressure easily' $(r=.47)$ and between exposure to friends' textual and visual intoxication references on social media $(r=.52)$. These changes resulted in an acceptable model fit $\left(\chi^{2}=4281.14, p<.001\right.$, RMSEA(CI) $=.06(.06 / .06)$, $\mathrm{CFI}=.85, \mathrm{TLI}=.84, \mathrm{SRMR}=.07, \mathrm{AIC}=80515.98)$. Additional reliability analyses demonstrated the scales were reliable after removing these items (see Table 1).

\section{Analyses}

Mplus version 8 was used for all analyses except reliability, multicollinearity and normality analyses, which were conducted with SPSS 26. Multicollinearity was checked following Field (2009) and not found to be a problem: The largest VIF was well below 10 (VIF =1.66); the average VIF was 1.35 , which is not substantially greater than 1 ; and the tolerance was at least .2 for all variables ( smallest tolerance $=.60$ ). Tests of normality indicated that our sharing measure was positively skewed (skewness $=1.86$, Kolmogorov-Smirnov $=.18, p<.001$ ) and drinking intentions were negatively skewed ( skewness $=-.87$, Kolmogorov-Smirnov $=.12, p<.001$ ). To overcome this issue, all analyses were estimated using maximum likelihood estimation with robust standard errors using a numerical integration algorithm. Descriptive statistics and zero-order correlation analyses were calculated before testing the hypotheses.

\section{Results}

\section{Descriptive Statistics}

Table 1 displays the descriptive statistics and zero-order correlation. Of the respondents in this sample, $17.6 \%$ indicated they never share alcohol references on social media, while the majority of the respondents indicated they share alcohol references at least a few times a year. About onefourth of the respondents shared alcohol references at least once per month. Most respondents in our sample indicated that they intend to consume alcohol in the foreseeable future. Only $2.4 \%$ indicated that they definitely did not intend to consume any alcohol whatsoever. Table 2 displays the distributions of the frequency of self-sharing and drinking intentions by different levels ${ }^{2}$ of sensation seeking, sensitivity to peer pressure and self-control. 
Table 1. Descriptive Statistics and Bootstrapped (1,000 samples) Correlation Analyses

\begin{tabular}{|c|c|c|c|c|c|c|c|c|c|}
\hline & 1 & 2 & 3 & 4 & 5 & 6 & 7 & 8 & 9 \\
\hline $\begin{array}{l}\text { 1. Sharing alcohol } \\
\text { references online }\end{array}$ & & & & & & & & & \\
\hline $\begin{array}{l}\text { 2. Exposure to alcohol } \\
\text { references }\end{array}$ & $.51 * * *$ & & & & & & & & \\
\hline $\begin{array}{l}\text { 3. Intention to } \\
\text { consume alcohol }\end{array}$ & $.35 * * *$ & $.30 * * *$ & & & & & & & \\
\hline 4. Sensation seeking & $.25 * * *$ & $.24 * * *$ & $.39 * * *$ & & & & & & \\
\hline $\begin{array}{l}\text { 5. Sensitivity to peer } \\
\text { pressure }\end{array}$ & $.42 * * *$ & $.33 * * *$ & $.41 * * *$ & $.35 * * *$ & & & & & \\
\hline 6. Self-control & $-.25 * * *$ & $-.16 * * *$ & $-.34 * * *$ & $-.38 * * *$ & $-.48 * * *$ & & & & \\
\hline 7. Drinking behaviour & $.33 * * *$ & $.32 * * *$ & $.60 * * *$ & $.35 * * *$ & $.37 * * *$ & $-.31 * * *$ & & & \\
\hline 8. Age & .04 & .08 & .06 & .04 & $.09 *$ & .03 & -.03 & & \\
\hline 9. Gender (Male = 0) & $-.20 * * *$ & $-.17^{* * *}$ & $-.16 * * *$ & $-.24 * * *$ & $-.33^{* * *}$ & $.18 * * *$ & $-.35 * * *$ & $-.11^{* *}$ & \\
\hline $\begin{array}{l}\text { 10. Accommodation } \\
\text { (with parents = 0) }\end{array}$ & .01 & .04 & $.16^{* * *}$ & $.11^{* *}$ & .01 & .04 & .05 & $.13^{* * *}$ & .06 \\
\hline$M(S D)$ & $.8(.9)$ & $1.8(1.2)$ & $3.8(1.0)$ & $3.1(0.8)$ & $2.1(0.6)$ & $3.1(.6)$ & $1.3(1.2)$ & $20.9(1.6)$ & \\
\hline Median (IQR) & $.5(.9)$ & $1.5(1.7)$ & $4.0(1.5)$ & $3.2(1.0)$ & $2.1(0.8)$ & $3.1(.8)$ & $1.0(2.0)$ & $21.0(2.0)$ & \\
\hline Cronbach's Alpha & .95 & .94 & .92 & .76 & .83 & .82 & & & \\
\hline
\end{tabular}

Note. ${ }^{* * *} p<.001, * * p<.01,{ }^{*} p<.05$; results reported in the tables reflect measures as included in the final analysis. 
Table 2. Distributions of Self-Sharing and Drinking Intentions by Different Levels of Sensation Seeking, Sensitivity to Peer Pressure, and Self-Control

\begin{tabular}{|c|c|c|c|c|c|c|c|c|c|c|}
\hline & \multicolumn{5}{|c|}{ Self-sharing } & \multicolumn{5}{|c|}{ Drinking intentions } \\
\hline & $M(S D)$ & $\begin{array}{c}\text { Median } \\
\text { (IQR) }\end{array}$ & $\begin{array}{l}\text { Min - } \\
\text { Max }\end{array}$ & $\begin{array}{c}\% \text { above } \\
0\end{array}$ & $\begin{array}{c}\% \text { above } \\
\text { sample } M^{a}\end{array}$ & $M(S D)$ & $\begin{array}{c}\text { Median } \\
\text { (IQR) }\end{array}$ & $\begin{array}{l}\text { Min - } \\
\text { Max }\end{array}$ & $\begin{array}{c}\% \text { at } \\
\text { least } 3^{b}\end{array}$ & $\begin{array}{c}\% \text { above } \\
\text { sample } M^{c}\end{array}$ \\
\hline \multicolumn{11}{|l|}{ Sensation seeking } \\
\hline $\operatorname{Low}(N=102)$ & $0.5(0.7)$ & $0.3(0.6)$ & $0-4.9$ & 76.5 & 20.8 & $3.1(1.1)$ & $3.2(1.7)$ & $1-5$ & 52.7 & 29.3 \\
\hline Medium $(N=438)$ & $0.8(0.8)$ & $0.5(0.9)$ & $0-4.5$ & 83.3 & 38.5 & $3.8(1.0)$ & $4.0(1.3)$ & $1-5$ & 83.6 & 60.3 \\
\hline $\operatorname{High}(N=98)$ & $1.1(1.1)$ & $0.8(1.1)$ & $0-5.4$ & 84.3 & 48.6 & $4.4(0.8)$ & $4.5(0.8)$ & $1-5$ & 97.0 & 85.5 \\
\hline \multicolumn{11}{|c|}{ Sensitivity to peer pressure } \\
\hline Low $(N=117)$ & $0.3(0.4)$ & $0.2(0.5)$ & $0-1.5$ & 66.7 & 16.4 & $3.2(1.1)$ & $3.2(1.8)$ & $1-5$ & 56.4 & 32.5 \\
\hline Medium $(N=411)$ & $0.7(0.8)$ & $0.5(0.8)$ & $0-5.4$ & 84.2 & 36.0 & $3.8(1.0)$ & $4.0(1.5)$ & $1-5$ & 83.5 & 60.8 \\
\hline $\operatorname{High}(N=110)$ & $1.5(1.2)$ & $1.3(1.5)$ & $0-4.9$ & 92.7 & 60.0 & $4.4(0.7)$ & $4.6(1.0)$ & $2.7-5$ & 96.4 & 81.8 \\
\hline \multicolumn{11}{|l|}{ Self-control } \\
\hline $\operatorname{Low}(N=109)$ & $1.0(1.0)$ & $0.8(1.3)$ & $0-5.4$ & 87.2 & 44.0 & $4.3(0.9)$ & $4.5(0.8)$ & $1-5$ & 91.7 & 79.8 \\
\hline Medium $(N=424)$ & $0.8(0.9)$ & $0.6(1.0)$ & $0-4.9$ & 83.0 & 39.6 & $3.8(1.0)$ & $4.0(1.5)$ & $1-5$ & 83.0 & 60.8 \\
\hline $\operatorname{High}(N=105)$ & $0.4(0.5)$ & $0.3(0.6)$ & $0-3.0$ & 75.2 & 15.2 & $3.2(1.1)$ & $3.3(1.6)$ & $1-5$ & 60.0 & 31.4 \\
\hline
\end{tabular}

Note. ${ }^{\text {a }}$ Sharing alcohol references $M_{\text {sample }}=0.8, S D=0.9 .{ }^{\mathrm{b}}$ Individuals indicating they at least 'maybe' intend to consume alcohol. ${ }^{\mathrm{c}}$ Drinking intentions $M_{\text {sample }}=3.8, \mathrm{SD}=1.0$. 


\section{Hypotheses Testing}

To test our hypotheses, the variables were entered in two steps into the model: In a first step, the direct relationships between our variables of interest were examined $\left(R^{2}=.46, \mathrm{AIC}=80322.49\right)$, and in a second step, the latent interactions were added to test whether the model fit would improve, which it did $\left(R^{2}=.55, \mathrm{AIC}=80293.70\right)$. The direct relationships did not significantly change when adding the latent interactions. In particular, we found that more frequent sharing of alcohol references, higher levels of sensation seeking, being female, having consumed more alcohol in the past and not living with family were each associated with greater drinking intentions (see Table 3). The positive relationship between sensitivity to peer pressure and drinking intentions was only marginally significant, and the negative relationship between self-control and drinking intentions was not significant. Thus, Hypothesis 1 was only partially supported, but Hypothesis 2 was confirmed.

When looking at the latent interactions, significant negative interactions between sharing alcohol references and sensation seeking, as well as between sharing alcohol references and sensitivity to peer pressure, can be observed (see Table 3). This means that the association between sharing alcohol references on social media and alcohol consumption is the strongest for individuals with the lowest levels of sensation seeking or sensitivity to peer pressure, and the strength of this relationship decreases as levels of sensation seeking or sensitivity to peer pressure increase. There was no significant interaction between sharing alcohol references and self-control. The conditional effect of sharing alcohol references on drinking intention for the three moderators is visually

Table 3. Interaction Analyses Between Sharing Alcohol References on Social Media and Sensation Seeking, Sensitivity to Peer Pressure, and Self-Control

\begin{tabular}{lcccc}
\hline & \multicolumn{3}{c}{ Drinking intention } \\
\cline { 2 - 4 } & \multicolumn{1}{c}{$\beta(S E)$} & $\beta / S E$ & $L L C l$ & ULCI \\
\hline Sharing alcohol references & $.31(.05)^{* * *}$ & 5.92 & .21 & .42 \\
Sensation seeking & $.16(.06)^{* *}$ & 2.83 & .05 & .27 \\
Sensitivity to peer pressure & $.11(.06)^{\dagger}$ & 1.91 & .00 & .22 \\
Self-control & $-.05(.05)$ & -0.86 & -.15 & .06 \\
Gender & $.11(.04)^{* *}$ & 2.99 & .04 & .17 \\
Age & $.05(.03)$ & 1.56 & -.01 & .11 \\
Prior drinking behaviour & $.51(.04)^{* * *}$ & 13.51 & .44 & .59 \\
Exposure to alcohol references & $-.02(.05)$ & -0.39 & -.11 & .07 \\
Accommodation & $.12(.03)^{* * *}$ & 3.66 & .06 & .18 \\
Sharing X sensation seeking & $-.13(.04)^{* *}$ & -2.93 & -.21 & -.04 \\
Sharing X sensitivity to peer pressure & $-.10(.04)^{* *}$ & -2.74 & -.17 & -.03 \\
Sharing X self-control & $.01(.05)$ & 0.15 & -.09 & .10 \\
\hline Model & $R^{2}=.55, p<.001, \mathrm{AIC}=80293.70$ & \\
\hline Note. ${ }^{* * *} p<.001, * * p<.01,{ }^{*} p<.05,+p<.06 . \mathrm{LLCl}=$ lower limit confidence interval; ULCl $=$ upper limit confidence \\
interval.
\end{tabular}



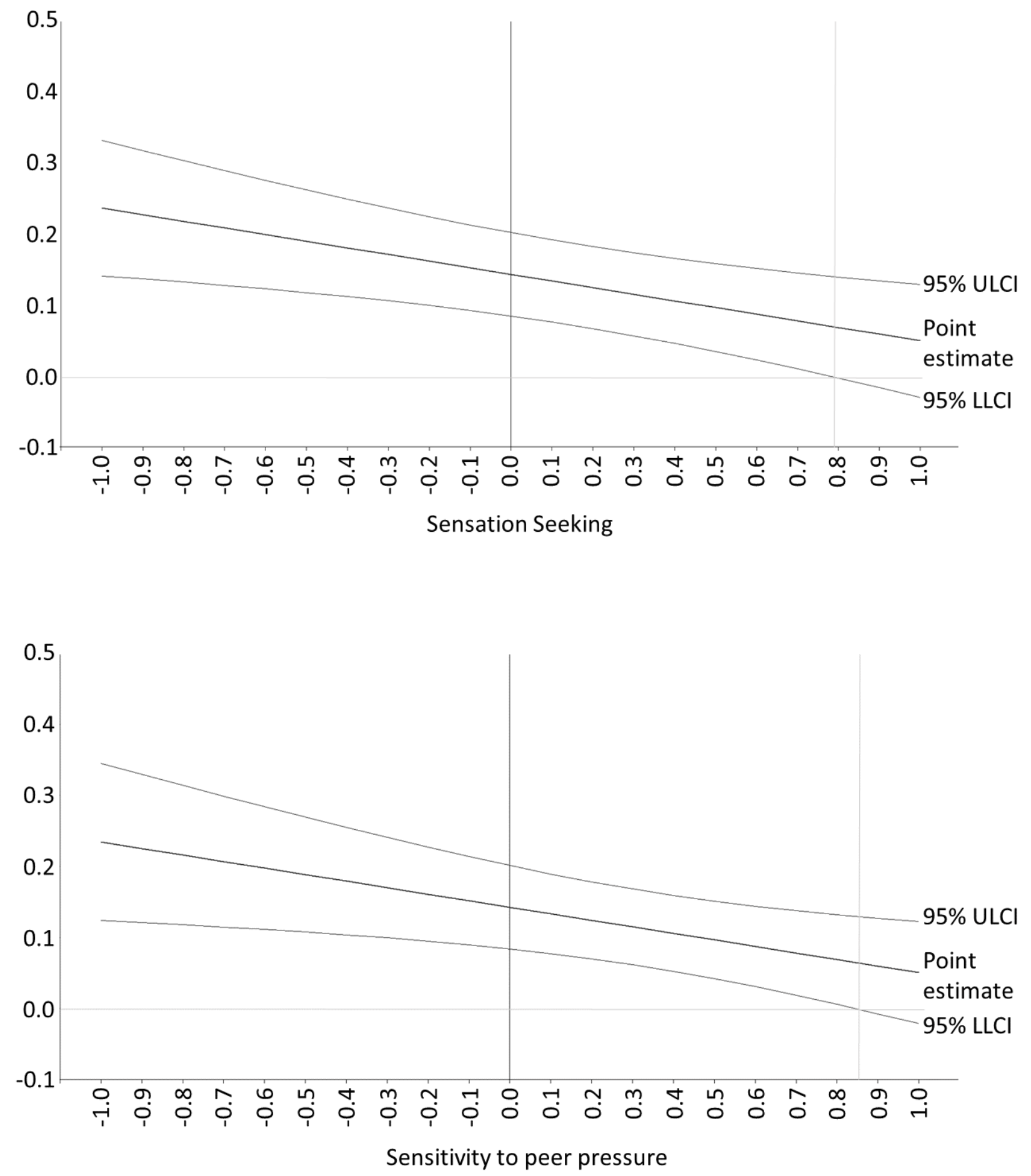

Figure 1. The conditional effect of sharing alcohol references on social media on drinking intention as a function of the levels of sensation seeking, sensitivity to peer pressure, and self-control 


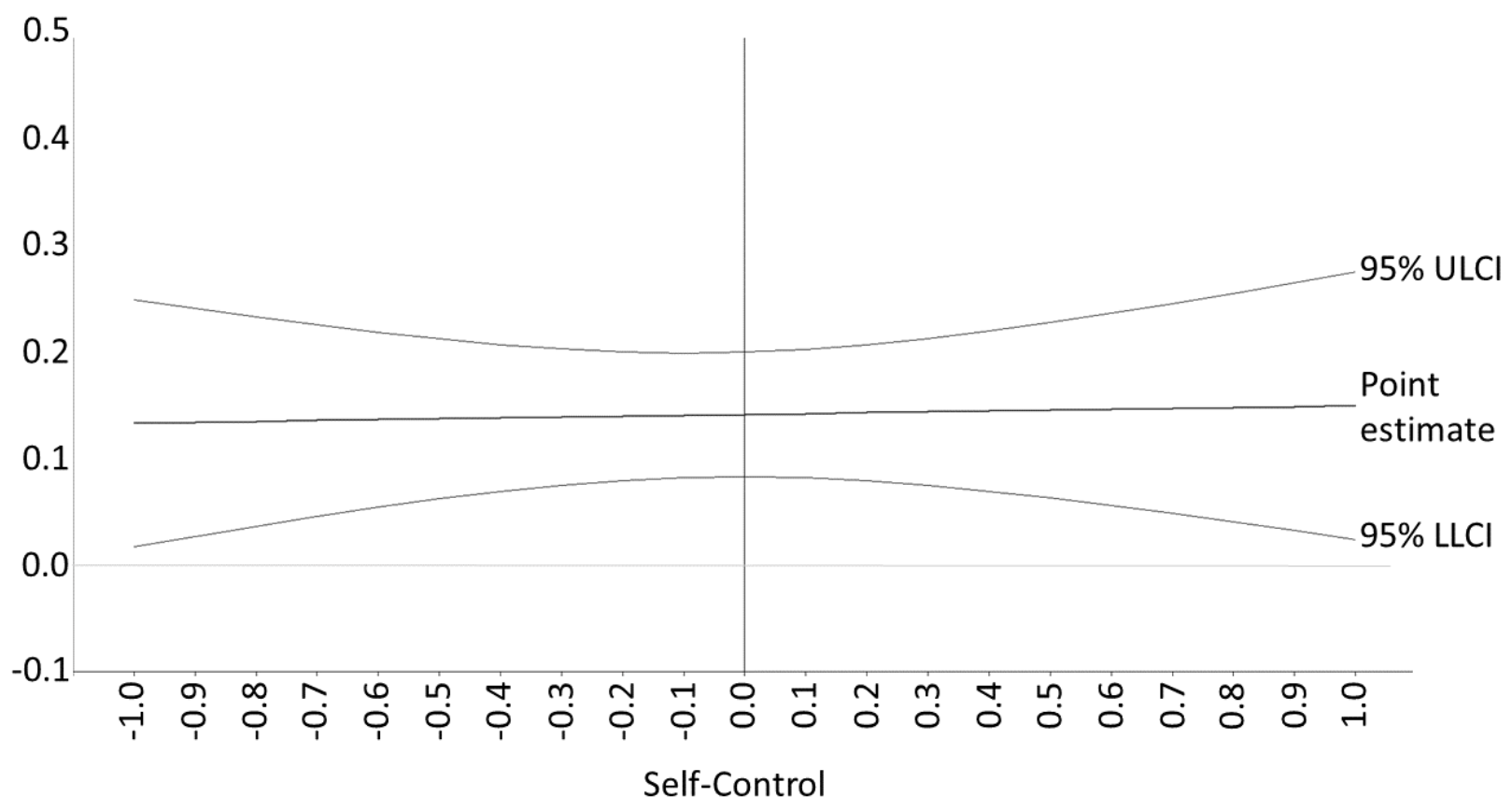

Figure 1. continued

represented in Figure 1. This figure demonstrates that the relationship between sharing alcohol references and drinking intention fails to reach significance for individuals who score approximately .80 SD above the mean or higher for sensation seeking and sensitivity to peer pressure.

\section{Discussion}

The goal of this study was to refine our understanding of alcohol-related social media self-effects by answering the call to investigate the potential conditionality of media effects (e.g., Krcmar, 2009; Slater, 2004; Valkenburg \& Peter, 2013). We aimed to assess for which subgroups alcoholrelated communication on social media can be used to identify potential risky drinking behaviour. Extending prior research (D’Angelo et al., 2014; Geusens \& Beullens, 2017b, 2018; Ridout et al., 2012), this study found that individuals who share alcohol references on social media more frequently have stronger drinking intentions. Although the present study cannot make any causal claims due to its cross-sectional nature, our findings suggest that - at least for the average college student - self-sharing alcohol references can be related to intentions to engage in (heavy) drinking behaviour. Consequently, our findings support the proposition that alcohol references on social media could potentially be used to identify individuals with greater intentions to engage in heavy drinking behaviour. Intentional heavy drinking is not uncommon during emerging adulthood, and drinking intentions are one of the biggest risk factors of heavy drinking behaviour among this age group (Cooke et al., 2016; French \& Cooke, 2012). Demonstrating that online alcohol-related communication can tap into this intentionality is an important step forward in trying to understand the role of alcohol-related social media use in emerging adults' heavy drinking behaviour. 
Beyond this new insight into the association between self-sharing alcohol references and drinking intentions, we are among the first to empirically demonstrate that the strength of these alcohol-related social media self-effects is conditional. Although most researchers acknowledge the theoretical proposition that media effects are dependent on individual-difference variables, empirical studies implementing these propositions remain limited within the field of risk- and health-related social media use. It is crucial to study media-effect conditionality to better understand the size and nature of media effects on individuals (Valkenburg \& Peter, 2013). Our findings confirm the conditionality proposition, demonstrating that the strength of the association between alcohol-related self-sharing on social media and individuals' drinking intentions can be dependent on users' personality traits. Specifically, we find that the relationship between selfsharing and drinking intentions is strongest for individuals with low-risk personality traits and gradually declines in strength as individuals are more inherently motivated to engage in risky drinking behaviour.

From a more theoretical perspective, our findings demonstrate the importance of incorporating conditionality in media-effects research. The traditional stimulus-response operationalization of the relationship between alcohol-related social media use and drinking-related behaviours and cognitions that is usually adopted appears to paint an incomplete and oversimplified picture of this association. Specifically, while a weak to moderate association is found for the average college student (i.e., the classic operationalization of the relationship), individuals with high-risk personality traits experience the weakest or even no relationship between self-sharing alcohol references and drinking intentions, and those with low-risk personality traits experience the strongest relationship. Thus, while many may instinctively reason that those who are predisposed to engage in risk behaviour will also experience the strongest relationship between risk-related social media use and risk-related cognitions, we demonstrate that - at least for alcohol-related social media effects - the relationship is not necessarily reflective of what would be expected under a sustained downward-spiral model of effects.

Nevertheless, not all differential susceptibility factors exerted the same moderating influence on the relationship between self-sharing and drinking intentions: Whereas sensation seeking and sensitivity to peer pressure were both significant moderators, self-control was not. In the past, selfcontrol has been found to predict a wide range of behaviours, including school- and work-related behaviours, eating and weight, interpersonal functioning and well-being and adjustment (de Ridder et al., 2012), but we could not replicate this finding. While we did find self-control to be negatively related to intentions to consume alcohol at the zero-order level (see Table 1), this relationship was not maintained in the regression model. It is possible that the variance of self-control was already explained by the other personality traits in the model. Indeed, an alternative model with only selfcontrol found self-control to be both a significant direct predictor $(\beta=-.15, p<.001)$ and a significant moderator $(\beta=.13, p<.001)$. This demonstrates the importance of testing multiple differential susceptibility factors simultaneously, as they can be interdependent.

This finding also demonstrates the importance of systematically testing a range of different personality traits in order to create a profile of an individual at risk. For instance, extending our sensitivity to peer pressure finding, fear of missing out, or 'FoMO', has been related to experiencing more negative alcohol-related outcomes (Riordan et al., 2015) and taps into the social aspects of both alcohol consumption and social media. Likewise, sensation seeking is both part of 
a larger personality construct of impulsivity and entails different sub-constructs itself (Hoyle et al., 2002; Stautz \& Cooper, 2013). It would be compelling to compare the different facets of impulsivity (i.e., sensation seeking, lack of premeditation or perseverance, positive and negative urgency) and different facets of sensation seeking (i.e., experience seeking, boredom susceptibility, thrill and adventure seeking and disinhibition) to see which aspects are most important in alcohol-related social media effects.

In addition, it appears important to take a developmental perspective when testing individual differences in alcohol-related social media effects. While our study found support for the desensitization hypothesis, prior research among a much younger sample with comparatively low alcohol consumption and alcohol-related sharing behaviour found support for a downward-spiral model when examining the five-factor model as a moderator (Geusens, Vangeel, et al., 2019). Taken together, these opposing findings hint that the role of differential susceptibility variables is dependent on a respondent's age and drinking experience, and thus changes over time. It is possible that dispositionally high-risk individuals first experience a downward-spiral model, which flattens as they age until they are desensitized to the media content and experience ceiling effects due to their dispositionally high drinking behaviour. If future research would adopt a longitudinal approach and follow individuals as they transition through the different phases of adolescence into adulthood to test this claim, this would significantly improve our comprehension of how media effects interact with dispositional vulnerability factors.

From a more practical perspective, we have identified a group at risk for heavy drinking behaviour that is not usually targeted by prevention and intervention initiatives. In particular, traditionally low-risk individuals experience the strongest relationship between sharing alcoholrelated content and drinking intentions. Considering that drinking intentions are good predictors of heavy drinking behaviours (Cooke et al., 2016; Norman et al., 2007), and individuals often consume more alcohol than they originally intended (Trim et al., 2011), this finding calls for more attention to the potential vulnerability of individuals who are generally considered relatively 'safe' by prevention and intervention workers. Further, these results suggest that the sharing of alcohol references on social media may be a promising behavioural indicator for this overlooked segment, which can be used by health workers to identify individuals at risk for the negative consequences of alcohol consumption.

To date, many personality-targeting prevention and intervention initiatives focus on high-risk individuals. These initiatives have been shown to be effective in reducing risky drinking behaviour because they use personality-targeted messages in personality-targeted environments (Lammers et al., 2017; Newton et al., 2016). However, individuals with low-risk personality traits who are at risk for heavy drinking behaviour because of their online sharing behaviour may not respond to interventions and prevention campaigns targeted at youth with personality traits opposing their own. Consequently, it may be necessary to establish more personality-appropriate messages and environments to protect this second group at risk, while continuing to target traditionally high-risk individuals with existing targeted intervention approaches that have been shown to be effective. Although more research is needed to substantiate this claim, media literacy programs to reduce alcohol-related sharing behaviour could potentially diminish drinking intentions among traditionally low-risk students. Nevertheless, we should be careful in implementing prevention or 
intervention techniques without a solid theoretical basis and substantial experimental tests, as these have been known to backfire, causing a boomerang effect (Stibe \& Cugelman, 2016).

Taken together, the findings of this study indicate that for the current generation of digitally connected youth, alcohol-related communication on social media appears to play a role in their drinking behaviour. It appears that individuals who frequently share alcohol references can be identified as having heavy drinking intentions, although not all individuals with high drinking intentions frequently share alcohol references. Thus, both prevention practitioners and researchers interested in health-related behaviours should take into account that young people do not only communicate face to face, and computer- (or smartphone-) mediated communication should not be ignored when studying drinking behaviour.

\section{Limitations}

As with all research, this study has several shortcomings. First, this study relied on self-reports. It is possible that some respondents over- or under-reported their drinking intentions or their engagement with alcohol-related content on social media due to social desirability bias. Based on the current data, we cannot determine the extent to which these self-reports reflect actual behaviour, but previous research has indicated that self-reports of risk behaviour are usually reliable (Flisher et al., 2004). Second, the sample under examination consisted of Belgian college students. Belgium is known to be relatively tolerant in its alcohol policy for adolescents, especially when compared to other countries such as the United States, which has a comparatively restrictive alcohol policy. Nevertheless, recent research comparing college students from Belgium with college students from the United States indicated that alcohol-related social media effects appear to operate similarly in both populations, despite the differences in drinking culture (Geusens, Bigman-Galimore, et al., 2019).

Third, we focused on drinking intentions as the outcome, rather than drinking behaviour, and the intention-behaviour gap argues that intentions may not always result in behaviour (Sheeran \& Webb, 2016). However, it has been shown that when behaviour is easy or fun - as is alcohol consumption for young individuals - it is more likely that intentions are enacted (Sheeran \& Webb, 2016). Fourth, the sample was collected through 30 senior undergraduate students following a quantitative research course. Though this had the advantage of being able to reach students from all over the country who did not study at the authors' institution, it has the disadvantage that it is possible that the sample is biased, because these students' social networks were not random. We attempted to mitigate this bias by using 30 different students who did not participate in the study themselves and were each asked to recruit a student sample that was as diverse as possible.

Fifth, we did not focus on specific media platforms. This decision was made to overcome the difficulty of a rapidly changing media landscape in which social media platforms constantly surface, change and disappear, entailing the risk that research focusing on specific attributes of specific platforms that exist today may no longer be relevant in five years. Nevertheless, our operationalization may miss some of the nuances that focusing on specific platforms can engender (Vranken et al., in press). For instance, Snapchat and Instagram appear to be preferred over Facebook to share alcohol-related content; glamourized alcohol-related content is preferred on Instagram, and more negative alcohol-related content is reserved for Snapchat (Boyle et al., 2017). Sixth, we used the number of drinks on a typical drinking day as a control variable, instead of 
binge drinking frequency. Finally, the cross-sectional design of this study does not allow us to test whether the alcohol references on social media affect the drinking intentions and subsequent drinking behaviour of individuals. However, research by Geusens and Beullens (2017b) showed that the relationship between alcohol-related social media use and drinking behaviour is reciprocal. Finally, as we discussed earlier, there are other personality traits that can play a role in students' drinking behaviour, such as the five-factor model (Hakulinen et al., 2015), impulsivity (Stautz \& Cooper, 2013) or FoMO (Riordan et al., 2015), which could be pursued in future research.

\section{Conclusion}

The current study is among the first to show that the positive association between sharing alcohol references on social media and drinking intention is strongest for those with low levels of sensation seeking and sensitivity to peer pressure. For individuals with the highest levels of sensation seeking and sensitivity to peer pressure, there was no significant relationship between sharing alcohol references on social media and their drinking intentions. This may be explained by a ceiling effect, whereby the drinking intentions of high-risk personality profiles were already relatively high. We conclude that by addressing the conditionality of media effects, health communication researchers can gain a better understanding of the magnitude of media effects on specific subgroups of individuals.

\section{Notes}

1. Prior research in the population under consideration showed that going-out behaviour is intrinsically linked to alcohol consumption in individuals' minds (Rosiers et al., 2014): In Dutch, the language in which the survey was administered, the meaning of 'going out' has a connotation of partying and going to the pub to drink. This proposition was supported, as no significant differences were found when testing an alternative model incorporating only the alcohol-related items in the social media scales (i.e., and not the going-out items). Consequently, the full alcohol-related social media items scale was used in our analyses, including the going-out references.

2. Throughout this manuscript, scoring 'low' is operationalized as scoring at least 1 SD below the mean, and scoring 'high' is operationalized as scoring at least $1 \mathrm{SD}$ above the mean.

\section{Funding}

This work was supported by grants from Bijzonder Onderzoeksfonds KU Leuven / Research Fund KU Leuven (Grant Numbers STG/14/012 and C12/16/008). 


\section{References}

Ajzen, I. (1991). The theory of planned behavior. Organizational Behavior and Human Decision Processes, 50, 179-211. https://doi.org/10.1016/0749-5978(91)90020-T

Arnett, J. J. (2005). The developmental context of substance use in emerging adulthood. Journal of Drug Issues, 35(2), 235-254. https://doi.org/10.1177/002204260503500202

Bem, D. J. (1972). Self-perception theory. In L. Berkowitz (Ed.), Advances in experimental social psychology (6th ed., pp. 1-62). Academic Press.

Beullens, K., \& Schepers, A. (2013). Display of alcohol use on Facebook: A content analysis. Cyberpsychology, Behavior and Social Networking, 16(7), 497-503. https://doi.org/10.1089/cyber.2013.0044

Beullens, K., \& Vandenbosch, L. (2016). A conditional process analysis on the relationship between the use of social networking sites, attitudes, peer norms and adolescents' intentions to consume alcohol. Media Psychology, 19(2), 310-333. https://doi.org/10.1080/15213269.2015.1049275

Boyle, S. C., Earle, A. M., LaBrie, J. W., \& Ballou, K. (2017). Facebook dethroned: Revealing the more likely social media destinations for college students' depictions of underage drinking. Addictive Behaviors, 65, 63-67. https://doi.org/10.1016/j.addbeh.2016.10.004

Colby, S. M., Colby, J. J., \& Raymond, G. A. (2009). College versus the real world: Student perceptions and implications for understanding heavy drinking among college students. Addictive Behaviors, 34, 17-27. https://doi.org/10.1016/j.addbeh.2008.07.023

Cooke, R., Dahdah, M., Norman, P., \& French, D. P. (2016). How well does the theory of planned behaviour predict alcohol consumption? A systematic review and meta-analysis. Health Psychology Review, 10(2), 148-167. https://doi.org/10.1080/17437199.2014.947547

Coskunpinar, A., Dir, A. L., \& Cyders, M. A. (2013). Multidimensionality in impulsivity and alcohol use: A meta-analysis using the UPPS model of impulsivity. Alcoholism: Clinical and Experimental Research, 37, 1441-1450. https://doi.org/10.1111/acer.12131

Cramer, D., \& Howitt, D. (2004). The SAGE dictionary of statistics: A practical resource for students in the social sciences. SAGE Publications.

Crawford, L. A., \& Novak, K. B. (2006). Alcohol abuse as a rite of passage: The effect of beliefs about alcohol and the college experience on undergraduates' drinking behaviors. Journal of Drug Education, 36(3), 193-212. https://doi.org/10.2190/F0X7-H765-6221-G742

Curtis, B. L., Lookatch, S. J., Ramo, D. E., McKay, J. R., Feinn, R. S., \& Kranzler, H. R. (2018). Meta-analysis of the association of alcohol-related social media use with alcohol consumption and alcohol-related problems in adolescents and young adults. Alcoholism: Clinical and Experimental Research, 42(6), 978-986. https://doi.org/10.1111/acer.13642

D’Angelo, J., Kerr, B., \& Moreno, M. A. (2014). Facebook displays as predictors of binge drinking: From the virtual to the visceral. Bulletin of Science, Technology \& Society, 34, 159169. https://doi.org/10.1177/0270467615584044

Daw, J., Shanahan, M., Harris, K. M., Smolen, A., Haberstick, B., \& Boardman, J. D. (2013). Genetic sensitivity to peer behaviors: 5HTTLPR, smoking, and alcohol consumption. Journal of Health and Social Behavior, 54(1), 92-108. https://doi.org/10.1177/0022146512468591 
De Bruyn, S., Wouters, E., Ponnet, K., Van Damme, J., Maes, L., \& Van Hal, G. (2018). Problem drinking among Flemish students: Beverage type, early drinking onset and negative personal \& social consequences. BMC Public Health, 18(1), 1-9. https://doi.org/10.1186/s12889-018-5120-7

de Ridder, D. T. D., Lensvelt-Mulders, G., Finkenauer, C., Stok, F. M., \& Baumeister, R. F. (2012). Taking stock of self-control: A meta-analysis of how trait self-control relates to a wide range of behaviors. Personality and Social Psychology Review, 16(1), 76-99. https://doi.org/10.1177/1088868311418749

Dormal, V., Bremhorst, V., Lannoy, S., Lorant, V., Luquiens, A., \& Maurage, P. (2018). Binge drinking is associated with reduced quality of life in young students: A pan-European study. Drug and Alcohol Dependence, 193, 48-54. https://doi.org/10.1016/j.drugalcdep.2018.08.033

Field, A. (2009). Discovering statistics using SPSS (3rd ed.). Sage.

Fishbein, M., \& Ajzen, I. (2010). Predicting and changing behavior: The reasoned action approach. Psychology Press.

Flisher, A. J., Evans, J., Muller, M., \& Lombard, C. (2004). Brief report: Test-retest reliability of self-reported adolescent risk behaviour. Journal of Adolescence, 27(2), 207-212. https://doi.org/10.1016/j.adolescence.2001.10.001

French, D. P., \& Cooke, R. (2012). Using the theory of planned behaviour to understand binge drinking: The importance of beliefs for developing interventions. British Journal of Health Psychology, 17(1), 1-17. https://doi.org/10.1111/j.2044-8287.2010.02010.x

Funk, J. B. (2013). Media violence, desensitization, and psychological engagement. In K. E. Dill (Ed.), The Oxford handbook of media psychology (pp. 1-22). Oxford University Press. https://doi.org/10.1093/oxfordhb/9780195398809.013.0012

Geusens, F., \& Beullens, K. (2017a). Strategic self-presentation or authentic communication? Predicting adolescents' alcohol references on social media. Journal of Studies on Alcohol and Drugs, 78, 124-133. https://doi.org/10.15288/jsad.2017.78.124

Geusens, F., \& Beullens, K. (2017b). The reciprocal associations between sharing alcohol references on social networking sites and binge drinking: A longitudinal study among late adolescents. Computers in Human Behavior, 73, 499-506. https://doi.org/10.1016/j.chb.2017.03.062

Geusens, F., \& Beullens, K. (2018). The association between social networking sites and alcohol abuse among Belgian adolescents: The role of attitudes and social norms. Journal of Media Psychology, 30, 207-216. https://doi.org/10.1027/1864-1105/a000196

Geusens, F., \& Beullens, K. (2019). A longitudinal examination of the moderating influence of peer and parental socialization on alcohol-related social media self-effects among late adolescents. Media Psychology, 22, 273-297. https://doi.org/10.1080/15213269.2018.1476159

Geusens, F., Bigman-Galimore, C. A., \& Beullens, K. (2019). A cross-cultural comparison of the processes underlying the associations between sharing of and exposure to alcohol references and drinking intentions. New Media \& Society, online fir.

https://doi.org/10.1177/1461444819860057

Geusens, F., Vangeel, J., Vervoort, L., van Lippevelde, W., \& Beullens, K. (2019). Dispositioncontent congruency in adolescents' alcohol-related social media (self-) effects: The role of the five-factor model. Journal of Studies on Alcohol and Drugs, 80, 631-640. https://doi.org/10.15288/jsad.2019.80.631 
Griffin, A. M., Cleveland, H. H., Schlomer, G. L., Vandenbergh, D. J., \& Feinberg, M. E. (2015). Differential susceptibility: The genetic moderation of peer pressure on alcohol use. Journal of Youth and Adolescence, 44(10), 1841-1853. https://doi.org/10.1007/s10964-0150344-7

Hakulinen, C., Elovainio, M., Batty, G. D., Virtanen, M., Kivimäki, M., Jokela, M., ... Jokela, M. (2015). Personality and alcohol consumption: Pooled analysis of 72,949 adults from eight cohort studies. Drug and Alcohol Dependence, 151, 110-114.

https://doi.org/10.1016/j.drugalcdep.2015.03.008

Harrington, D. (2009). Confirmatory factor analysis. Oxford University Press.

Hebden, R., Lyons, A. C., Goodwin, I., \& McCreanor, T. (2015). "When you add alcohol, it gets that much better": University students, alcohol consumption, and online drinking cultures. Journal of Drug Issues, 45(2), 214-226. https://doi.org/10.1177/0022042615575375

Hendriks, H., Gebhardt, W. A., \& van den Putte, B. (2017). Alcohol-related posts from young people on social networking sites: Content and motivations. Cyberpsychology, Behavior, and Social Networking, 20, 428-435. https://doi.org/10.1089/cyber.2016.0640

Hendriks, H., Van Den Putte, B., \& Gebhardt, W. A. (2018). Alcoholposts on social networking sites: The alcoholpost-typology. Cyberpsychology, Behavior, and Social Networking, 21, 463-467. https://doi.org/10.1089/cyber.2017.0729

Hittner, J. B., \& Swickert, R. (2006). Sensation seeking and alcohol use: A meta-analytic review. Addictive Behaviors, 31(8), 1383-1401. https://doi.org/10.1016/j.addbeh.2005.11.004

Hoyle, R. H., Stephenson, M. T., Palmgreen, P., Lorch, E. P., \& Donohew, R. L. (2002). Reliability and validity of a brief measure of sensation seeking. Personality and Individual Differences, 32(3), 401-414. https://doi.org/10.1016/S0191-8869(01)00032-0

Kenny, D. A. (2011). Respecification of latent variable models. Retrieved August 30, 2016, from http://davidakenny.net/cm/respec.htm

Kenny, D. A. (2016). Miscellaneous variables: Formative variables and second-order factors. Retrieved August 30, 2016, from http://davidakenny.net/cm/mvar.htm

Koning, I. M., Van Den Eijnden, R. J. J. M., Engels, R. C. M. E., Verdurmen, J. E. E., \& Vollebergh, W. A. M. (2011). Why target early adolescents and parents in alcohol prevention? The mediating effects of self-control, rules and attitudes about alcohol use. Addiction, 106(3), 538-546. https://doi.org/10.1111/j.1360-0443.2010.03198.x

Krcmar, M. (2009). Individual differences in media effects. In R. L. Nabi \& M. B. Oliver (Eds.), The SAGE handbook of media processes and effects (pp. 237-250). Sage.

Kubacki, K., Siemieniako, D., \& Rundle-Thiele, S. (2011). College binge drinking: A new approach. Journal of Consumer Marketing, 28(3), 225-233. https://doi.org/10.1108/07363761111127644

Lammers, J., Goossens, F., Conrod, P., Engels, R., Wiers, R. W., \& Kleinjan, M. (2017). Effectiveness of a selective alcohol prevention program targeting personality risk factors: Results of interaction analyses. Addictive Behaviors, 71, 82-88. https://doi.org/10.1016/j.addbeh.2017.02.030

Malouff, J. M., Thorsteinsson, E. B., Rooke, S. E., \& Schutte, N. S. (2007). Alcohol involvement and the five-factor model of personality: A meta-analysis. Journal of Drug Education, 37(3), 277-294. https://doi.org/10.2190/DE.37.3.d 
Moreno, M. A., Briner, L. R., Williams, A., Brockman, L., Walker, L., \& Christakis, D. A. (2010). A content analysis of displayed alcohol references on a social networking web site. Journal of Adolescent Health, 47(2), 168-175. https://doi.org/10.1016/j.jadohealth.2010.01.001

Moreno, M. A., Kacvinsky, L., Pumper, M., Wachowski, L., \& Whitehill, J. M. (2013). Associations between social media displays and event-specific alcohol consumption by college students. Wisconsin Medical Journal, 112(6), 251-256.

Mrug, S., \& Windle, M. (2014). DRD4 and susceptibility to peer influence on alcohol use from adolescence to adulthood. Drug and Alcohol Dependence, 145, 168-173.

https://doi.org/10.1016/j.drugalcdep.2014.10.009

Newton, N. C., Conrod, P. J., Slade, T., Carragher, N., Champion, K. E., Barrett, E. L., ... Teesson, M. (2016). The long-term effectiveness of a selective, personality-targeted prevention program in reducing alcohol use and related harms: A cluster randomized controlled trial. Journal of Child Psychology and Psychiatry and Allied Disciplines, 57(9), 1056-1065. https://doi.org/10.1111/jcpp.12558

Niland, P., Lyons, A. C., Goodwin, I., \& Hutton, F. (2014). "See it doesn't look pretty does it?" Young adults' airbrushed drinking practices on Facebook. Psychology \& Health, 29(8), 87795. https://doi.org/10.1080/08870446.2014.893345

Norman, P., Armitage, C. J., \& Quigley, C. (2007). The theory of planned behavior and binge drinking: Assessing the impact of binge drinker prototypes. Addictive Behaviors, 32(9), 17531768. https://doi.org/10.1016/j.addbeh.2006.12.009

Ouellette, J. A., \& Wood, W. (1998). Habit and intention in everyday life: The multiple processes by which past behavior predicts future behavior. Psychological Bulletin, 124(1), 54-74. https://doi.org/10.1037/0033-2909.124.1.54

Peluchette, J., \& Karl, K. (2009). Examining students' intended image on Facebook: "What were they thinking?!" Journal of Education for Business, 85(1), 30-37. https://doi.org/10.1080/08832320903217606

Ridout, B., Campbell, A., \& Ellis, L. (2012). “Off your Face(book)”: Alcohol in online social identity construction and its relation to problem drinking in university students. Drug and Alcohol Review, 31(1), 20-26. https://doi.org/10.1111/j.1465-3362.2010.00277.x

Riordan, B. C., Flett, J. A. M., Hunter, J. A., Scarf, D., \& Conner, T. S. (2015). Fear of missing out (FoMO): The relationship between FoMO, alcohol use, and alcohol-related consequences in college students. Journal of Psychiatry and Brain Functions, 2. https://doi.org/10.7243/2055-3447-2-9

Rosiers, J., Van Damme, J., Hublet, A., Van Hal, G., Sisk, M., Si Mhand, Y., \& Maes, L. (2014). In hogere sferen? Een onderzoek naar het middelgebruik bij Vlaamse studenten (Vol. 3). Retrieved from http://www.vad.be/assets/1697

Santor, D. A., Messervey, D., \& Kusumakar, V. (2000). Measuring peer pressure, popularity, and conformity in adolescent boys and girls: Predicting school performance, sexual attitudes, and substance abuse. Journal of Youth and Adolescence, 29(2), 163-182. https://doi.org/10.1023/a:1005152515264

Saunders, J. B., Aasland, O. G., Babor, T. F., de la Fuente, J. R., \& Grant, M. (1993). Development of the Alcohol Use Disorders Identification Test (AUDIT): WHO collaborative project on early detection of persons with harmful alcohol consumption. Addiction, $88(6)$, 791-804. https://doi.org/10.1111/j.1360-0443.1993.tb02093.x 
Savolainen, I., Oksanen, A., Kaakinen, M., Sirola, A., Miller, B. L., Paek, H. J., \& Zych, I. (2020). The association between social media use and hazardous alcohol use among youths: A four-country study. Alcohol and Alcoholism, 55(1), 86-95. https://doi.org/10.1093/alcalc/agz088

Sheeran, P., \& Webb, T. L. (2016). The intention - behavior gap. Social and Personality Psychology Compass, 10, 503-518. https://doi.org/10.1111/spc3.12265

Slater, M. D. (2004). Vulnerable teens, vulnerable times: How sensation seeking, alienation, and victimization moderate the violent media content-aggressiveness relation. Communication Research, 31(6), 642-668. https://doi.org/10.1177/0093650204269265

Slater, M. D. (2007). Reinforcing spirals: The mutual influence of media selectivity and media effects and their impact on individual behavior and social identity. Communication Theory, 17(3), 281-303. https://doi.org/10.1111/j.1468-2885.2007.00296.x

Slater, M. D., Henry, K. L., Swaim, R. C., \& Anderson, L. L. (2003). Violent media content and aggressiveness in adolescents: A downward spiral model. Communication Research, 30(6), 713-736. https://doi.org/10.1177/0093650203258281

Stautz, K., \& Cooper, A. (2013). Impulsivity-related personality traits and adolescent alcohol use: A meta-analytic review. Clinical Psychology Review, 33(4), 574-592. https://doi.org/10.1016/j.cpr.2013.03.003

Stibe, A., \& Cugelman, B. (2016). Persuasive backfiring: When behavior change interventions trigger unintended negative outcomes. In International conference on persuasive technology (pp. 65-77). https://doi.org/10.1007/978-3-319-31510-2_6

Tan, A. S. L. (2012). Through the drinking glass: An analysis of the cultural meanings of college drinking. Journal of Youth Studies, 15(1), 119-142. https://doi.org/10.1080/13676261.2011.630997

Tangney, J. P., Baumeister, R. F., \& Boone, A. L. (2004). High self-control predicts good adjustment, less pathology, better grades, and interpersonal success. Journal of Personality, 72(2), 271-324. https://doi.org/10.1111/j.0022-3506.2004.00263.x

Trim, R. S., Clapp, J. D., Reed, M. B., Shillington, A., \& Thombs, D. (2011). Drinking plans and drinking outcomes: Examining young adults' weekend drinking behavior. Journal of Drug Education, 41, 253-270. https://doi.org/10.2190/DE.41.3.b

Valkenburg, P. M. (2017). Understanding self-effects in social media. Human Communication Research, 43, 477-490. https://doi.org/10.1111/hcre.12113

Valkenburg, P. M., \& Peter, J. (2013). The differential susceptibility to media effects model. Journal of Communication, 63(2), 221-243. https://doi.org/10.1111/jcom.12024

Van Damme, J., Thienpondt, A., Rosiers, J., De Bruyn, S., Soyez, V., Sisk, M., ... Deforche, B. (2018). In hogere sferen? (Volume 4) Een onderzoek naar het middelengebruik bij Vlaamse studenten (Report). Vlaams expertisecentrum Alcohol en andere Drugs (VAD) https://www.vad.be/assets/in-hogere-sferen-volume-4-een-onderzoek-naar-hetmiddelengebruik-bij-vlaamse-studenten

Vranken, S., Geusens, F., Meeus, A., \& Beullens, K. (in press). The platform is the message? Exploring the relation between different social networking sites and different forms of alcohol use. Health and New Media Research.

Walters, G. D. (2000). Behavioral self-control training for problem drinkers: A meta-analysis of randomized control studies. Behavior Therapy, 31, 135-149. https://doi.org/10.1016/S00057894(00)80008-8 
Wicki, M., Kuntsche, E., \& Gmel, G. (2010). Drinking at European universities? A review of students' alcohol use. Addictive Behaviors, 35, 913-924.

https://doi.org/10.1016/j.addbeh.2010.06.015

Wills, T. A., \& Stoolmiller, M. (2002). The role of self-control in early escalation of substance use: A time-varying analysis. Journal of Consulting and Clinical Psychology, 70(4), 986-997. https://doi.org/10.1037/0022-006X.70.4.986

Wolpe, J. (1982). The practice of behavior therapy (3rd edition). Pergamon Press.

Yoo, W., Yang, J. H., \& Cho, E. (2016). How social media influence college students' smoking attitudes and intentions. Computers in Human Behavior, 64, 173-182.

https://doi.org/10.1016/j.chb.2016.06.061

Zajdow, G., \& MacLean, S. (2014). "I just drink for that tipsy stage”: Young adults and embodied management of alcohol use. Contemporary Drug Problems, 41(4), 522-535. https://doi.org/10.1177/0091450914567123

\section{Author Contributions}

FG and KB conceived of and designed the study together; FG coordinated the data collection, conducted the statistical analyses, interpreted the results, wrote the original manuscript and revised the manuscript; CB provided feedback on all manuscript and revision drafts; KB acquired funding, participated in the coordination of the study, and provided feedback on all manuscript and revision drafts. All authors read and approved the final manuscript.

\section{Author biographies}

Femke Geusens is a postdoctoral fellow funded by the Research Foundation Flanders (FWO Vlaanderen) and affiliated with the School for Mass Communication Research at the KU Leuven, Belgium. She is especially interested in media effects research in a health context, and her current research focuses on the role social media (e.g., Facebook, Instagram) can play in individuals' health risk behaviors, especially substance use. She defended her dissertation on the underlying processes and conditionality of alcohol-related social media effects among adolescents and emerging adults in October 2018.

Cabral A Bigman-Galimore is an associate professor affiliated with the department of Communication of the University of Illinois at Urbana-Champaign. Her research focuses on communication about risk and inequality. She is particularly interested in the influence that messages about comparative risk and inequality have on health and communication-related behavior.

Kathleen Beullens is an associate professor affiliated with the School for Mass Communication Research at KU Leuven, Belgium. Her research focuses on the (longitudinal) effects of different media uses on adolescents' and emerging adults' psychosocial well-being. As a researcher in media psychology, she aims to unravel the processes through which various forms of (social) media use are associated with health and risk-related outcomes (including alcohol use, smoking, risky driving). 